\title{
3.1 ON THE DETERMINATION OF FORECAST ERRORS ARISING FROM DIFFERENT COMPONENTS OF MODEL PHYSICS AND DYNAMICS
}

\author{
T. N. KRISHNAMURTI, J. SANJAY, A. K. MITRA AND T. S. V. VIJAYA KUMAR* \\ Florida State University, Tallahassee, Florida
}

\section{Introduction}

In this paper we address the issue of statistical determination of forecast errors that arise from the components of a model's dynamics and physics. In a straightforward weather (or seasonal climate) forecast it is generally possible to identify the nature of total errors of the model at a given geographical location at any vertical level for any particular variable such as temperature. The forecast validation requires an observed (analysis) field that needs to be reliable. A determination of contributions to the total errors from the model's component dynamics and physics are not that straightforward. If such information were available then it would provide insights on the deficiencies of the model. It may be possible to infer deficiencies in the vertical distribution of heating for a given physical parameterization - such a knowledge can convey information as to whether the level of heating is too low or too high in the model, whether the warming or cooling and moistening or drying are too strong or too weak in the model. This type of information can be extremely useful for exploring possible future improvements of the physical parameterization schemes in a given model. This paper attempts to bring out the systematic errors of a model's component physics and dynamics.

Numerous studies and conference proceedings contain accounts on the systematic errors of numerical models Heckley (1985) addressed the predictability of large-scale quasi-stationary motions of time scale longer than 30 days and transient motions of 3-10 day time scales in the tropical region and showed that the systematic error of the model has a structure similar to zonal wave number 1 . He also pointed out that those errors are highly sensitive to the convective heating distribution in the tropics. In another study, Boer (1984, 1993) addressed the spectral analysis of model errors in a spherical domain limiting to mid-latitude dynamics for extra-tropical forecasts. Kass et al. (1999) have addressed total tendency errors arising from the parameterization of unresolved scales in a climate model. Theirs was an effort to tune the parameterization schemes based on such total errors. In another interesting study, Milton et al. (2000) attributed model systematic errors to single components in the parameterization schemes using UKMO global NWP model.

The influence of the physical forcings of an atmosp-

*Corresponding author address: Dr. T.S.V. Vijaya Kumar, Dept. of Meteorology, Florida State University, Tallahassee, FL 32306. E-mail: vijay@met.fsu.edu. -heric general circulation model towards the reduction of systematic errors of tropical forecasts was examined by Mohanty and Ramesh (1995). They used a statistical measure to evaluate the forecast skill. Although a statistics based error finding scheme may not provide explicit information on how to correct a given physical parameterization, it still can provide major insights and guidance for doing that.

The vertical distributions of heating, moistening, and eddy convergence of fluxes contained in the various physical parameterization of a forecast model contain numerous uncertainties. The correction of such errors has been a slow process. In cumulus parameterization, inclusion of downdrafts has lead to some improvements (Molinari and Dudeck 1992). The specification of random stochastic clouds has also contributed to some improvements of radiation fluxes (Tiedtke 1993). Finding the nature of errors in the vertical distributions of parameterized physical processes is not very straightforward. The design of NASA's FIRE program, described in Curry et al. (2000), was tailored towards providing observational estimates of heating arising from radiative transfer processes. TOGA-COARE and GATE served the same purpose for the boundary layer fluxes and cumulus parameterization issues respectively (Webster and Lukas 1992).

A rather straightforward method is being proposed here that enables us to answer the above question in a statistical sense. In this paper we provide the methodology, the breakdown of the model components, independent tests of the proposed procedure using two separate data sets and a discussion of model's errors arising from its dynamical and physical components. We also point out some possible future extensions of research from this approach.

\subsection{Improving the performance of a single atmospheric model}

In this paper we describe a sequence of modeling exercises that enable us to improve a numerical prediction model.

1) Tendency budgets of forecasts, where it is possible to carry out a book keeping of model forecast tendencies of all the physical and dynamical components.

2) Track the total errors for a number of forecasts.

3) Define certain regression coefficients for each of the components of model physics and dynamics using information from a large sample of forecasts. These are simply computed using a multiple regression procedure where the total tendency 
errors are known. These coefficients are then used as multipliers for each term (at each horizontal and vertical location) of the model's component tendencies.

4) These coefficients, derived in step (iii), enable us to obtain the error contributions from different components of the model physics and dynamics at each location for each variable of the model.

5) The information obtained in step (iv) can in principle also provide the means to develop a stochastic dynamic forecast model with possibly a higher skill compared to the parent model.

\section{Tendency Budget}

The methodology for evaluation of the tendency budget is an extension of a recent study, Krishnamurti et al. (1996). An atmospheric global spectral model was used in that study for a number of NWP and seasonal forecast experiments. Figure 1 provides an outline of the tendency budget, i.e., bookkeeping of the model forecasts. At the end of each time step, the tendencies arising from each component of the model dynamics and physics are accumulated during a medium range forecast. Thus, at the end of a forecast, it is possible to assess the contributions to the total forecast tendency from the model's components of physics and dynamics. This is a rather straightforward procedure and is no more than a budget of a forecast. In our previous study (Krishnamurti et al. 1996), we had labeled these as "with and with" experiments, to contrast these from "with and without" experiments. In the later case one carries out experiments suppressing an area of physics entirely throughout a long-term integration. To state that 'the difference between a full experiment and an experiment where a feature is suppressed continually throughout a forecast provides information on that suppressed feature' is incorrect, since these with and without experiments do not recognize that in a nonlinear system all features interact, coexist and co-evolve continually. As an example, convection coexists continually with dynamics in a fully nonlinear model and the effects of convection would be better learned from this aforementioned tendency budget where the bookkeeping at the end of a time step includes the mutual interactions among all components of the full model. The notion of with and with computations is also implicit in a recent study of Williamson (2002) where he addresses the difference between simultaneous versus sequential computations of physics and dynamics in a climate model. The first part of this paper is based on that study.

\section{The Global Model}

The purpose of this paper is to extract the error profiles of a given model's physical parameterization and of its dynamical formulations. This is a preliminary exercise only. For this purpose we have used an earlier version of the FSU Global Spectral Model. The features of this model are given in Krishnamurti et al. (1998).

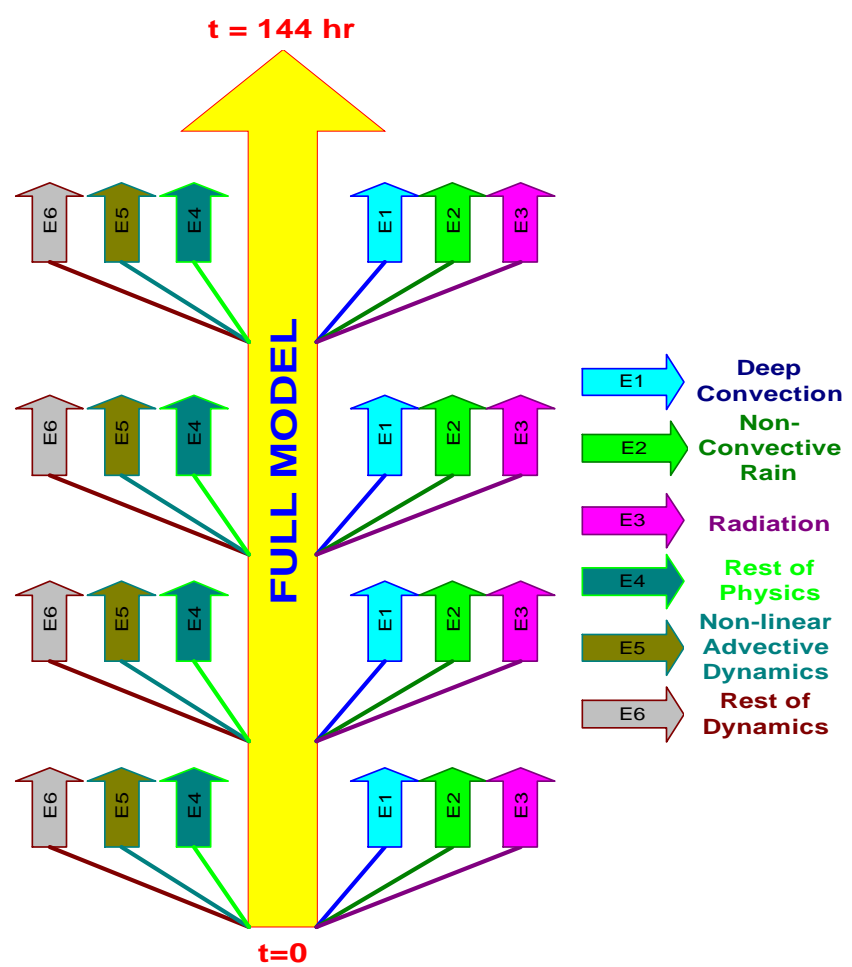

Fig. 1 A schematic diagram showing the methodology for partitioning of model components in the framework of with and with concept.

\section{Partitioning of Model Components}

The partitioning adopted in the present study is only one example to illustrate the working of the proposed methodology. In principle this can be extended to any degree of completeness and complexity. The present design of the partitioning includes 1) Nonlinear advective dynamics, 2) Rest of dynamics, 3) Deep cumulus convection, 4) Non convective rain, 5) Short wave and Long wave Radiation, and 6) Rest of physics. The model equations and methodology used in the partitioning are addressed in this section. Our interest here is on the advective dynamics, rest of dynamics and physics part of the equations. We shall first write down the terms representing advective dynamics total dynamics and the physics, as used in this paper. The rest of the dynamics was written simply as the difference of total dynamics and advective dynamics. The forcing due to physics was further separated into forcing due to deep convection, non-convective physics, radiation, and rest of the physics, which includes surface fluxes (air and land-sea intersection) and diffusive processes to separate the effect of various physical processes.

\subsection{Full model equations}

The basic prediction equations of the FSU model (Krishnamurti et al. 1998) used here involve the terms of advective dynamics, rest of dynamics, and physics and can be represented as: 
Momentum equation: (1)

$\frac{\partial \mathrm{V}}{\partial \mathrm{t}}=-\left[\mathrm{V} \cdot(\nabla \mathrm{V})+\varepsilon \frac{\partial \mathrm{V}}{\partial \bullet}\right]_{\mathrm{AD}}-\left[\mathrm{fk} \times \mathrm{V}+\mathrm{RT}^{\prime} \nabla \mathrm{q}\right]_{\mathrm{RD}}+[\mathrm{F}]_{\mathrm{PH}}$ Thermal equation: (2)

$\frac{\partial \mathrm{T}}{\partial \mathrm{t}}=-\left[\mathrm{V} \cdot(\nabla \mathrm{T})+\delta \frac{\partial \mathrm{T}}{\partial \bullet}\right]_{\mathrm{AD}}+\left[\bullet \frac{\mathrm{RT}}{\mathrm{C}_{\mathrm{P}} \mathrm{p}}\right]_{\mathrm{RD}}+\left[\mathrm{H}_{\mathrm{T}}\right]_{\mathrm{PH}}$

Moisture equation: (3)

$\frac{\partial \mathrm{S}}{\partial \mathrm{t}}=-\left[\mathrm{V} \cdot(\nabla \mathrm{S})+\frac{\partial \mathrm{S}}{\partial \cdot}\right]_{\mathrm{AD}}+\left[\frac{\dot{\mathrm{p}}}{\mathrm{p}}\left(\frac{\mathrm{RT}}{\mathrm{C}_{\mathrm{P}}}-\frac{\mathrm{RT}_{\mathrm{d}}^{2}}{\cdot \mathrm{L}\left(\mathrm{T}_{\mathrm{d}}\right)}\right)\right]_{\mathrm{RD}}+\left[\left(\mathrm{H}_{\mathrm{T}}-\mathrm{H}_{\mathrm{M}}\right)\right]_{\mathrm{PH}}$ and Surface pressure equation: (4)

$\frac{\partial \mathrm{q}}{\partial \mathrm{t}}=-[\mathrm{V} \cdot \nabla \mathrm{q}]_{\mathrm{AD}}-\left[\mathrm{D}+\frac{\partial \&}{\partial \bullet}\right]_{\mathrm{AD}}$

where $\mathbf{V}$ is the horizontal wind vector; $T$ is temperature; $\omega$ is $p$ vertical velocity; \&xis $\sigma$ vertical velocity; $q=\ln p_{s}$, $p_{s}$ being the surface pressure; $S=T-T_{d}$, dew point depression; $\mathbf{F}$ are frictional effects; $H_{T}$ is the diabatic heating effect; $H_{M}$ is the moisture sources and sinks effect; $R$ is the gas constant for dry air; $C_{p}$ is the specific heat of air at constant pressure; and $L\left(T_{d}\right)$ is the latent heat of water/ice at temperature $T_{d}$. In the above equations the terms marked by $A D, R D$, and $P H$ represent the advective dynamics, the rest of dynamics, and the physical processes, respectively.

In the FSU spectral model, the momentum equation (Eq. 1) is cast into vorticity and divergence equations. The respective equations are then transformed into their spectral form for model integration. Symbolically the above set of equations (Eqs. 1 to 4 ) can be represented as:
(5) $\frac{\partial \xi}{\partial t}=F_{\xi}(A D)+F_{\xi}(R D)+F_{\xi}(P H)=F_{\xi}$
(6) $\frac{\partial D}{\partial t}=F_{D}(A D)+F_{D}(R D)+F_{D}(P H)=F_{D}$
(7) $\frac{\partial T}{\partial t}=F_{T}(A D)+F_{T}(R D)+F_{T}(P H)=F_{T}$
(8) $\frac{\partial S}{\partial t}=F_{S}(A D)+F_{S}(R D)+F_{S}(P H)=F_{S}$
(9) $\frac{\partial q}{\partial t}=F_{q}(A D)+F_{q}(R D)+F_{q}(P H)=F_{q}$

where $F(A D), F(R D)$, and $F(P H)$ are the forcings due to the advective dynamics, the rest of dynamics, and the physical processes, respectively, and $F$ is the total forcing.

To study the effect of various forcing components on model forecasts, a number of model runs, each suppressing a specified forcing for one time step at a time, were executed in parallel with the normal model forecast run with full dynamics and physics. All model runs with partial dynamics or physics were carried out through only one time step at a time using the parent run's (with full dynamics and physics) spectral history files. The tendencies from each of these runs were next accumulated over each day to provide 24-h tendencies. In all, the following six parallel runs were made each ending at Day 6 using 1200 UTC initial conditions of every day during November and December 2001.
1) Expt. 0 normal run (full dynamics and physics)

2) Expt. 1 Expt. 0 -advective dynamics

3) Expt. 2 Expt. 0-full physics

4) Expt. 3 Expt. 0-deep convection

5) Expt. 4 Expt. 0 - stable rain

6) Expt. 5 Expt. 0 -radiation

7) Expt. 6 Expt. 0 -rest of physics

(surface fluxes, diffusion)

From these we get tendencies due to various forcing components as follows:
1. advective
expt. 0 - expt. 1
dynamics
2. full physics
3. rest of dynamics
expt. 0 - expt. 2
expt. 0 - (advective
dynamics + full physics)
4. deep convection
5. stable rain
6. radiation
expt. $0-$ expt. 3
expt. 0 - expt. 4
expt. $0-$ expt. 5
7. rest of physics

The details of such experimentation are given in Krishnamurti et al. (1996). In these experiments, the differences in total tendencies from "with and with" forecast runs provide the contribution to the tendency by one of the selected features such as advective nonlinear dynamics, rest of dynamics, deep cumulus convection, large-scale condensation physics, radiative transfers and rest of physics. The selection of features could have been extended into further number of categories, but were somewhat arbitrarily limited to those six categories only. It is important to note that the features that are suppressed are so done in the entire set of governing equations of the model. For instance the advective nonlinear dynamics appear in five prognostic equations, i.e., those of vorticity, divergence, log of surface pressure, temperature and moisture. When we suppress nonlinear dynamics, we do so in all of these five prognostic equations at the same time. Thus, the contribution to the tendencies from any of these features affects the tendencies of all five equations. After these experiments are carried through day six of forecasts, we accumulate the contributions to the tendencies over any desired forecast interval of interest. This 'with and with' strategy even permits, for example, things such as contribution to the temperature tendency arising from the nonlinear advection of moisture. Those two are not related through a single equation, but are inherently coupled in a nonlinear system and the accumulation of tendencies enables us to see these inter relationships.

Thus even a term, such as the accumulated tendencies from the nonlinear advection of temperatures, is affected by what goes on in the rest of the model dynamics and physics. These nonlinear feedbacks among the variables are affected even by a single forcing. In this paper, we will be taking the thermal equation as a centerpiece for finding the errors contributed by its different terms. The estimates of tendencies contributed by each of those terms are 
determined by following the proposed 'with and with' strategy. This exercise is repeated for each day for two months i.e. November and December of 2001 and the forecasts are carried out through day- 6 for each day.

Given the daily data set for the temperature tendencies over the globe (on the transform grid points at the spectral resolution T126), we next pursue a statistical approach to reduce these forecast errors and assess the contributions from the model dynamics and physics.

\subsection{The multipliers that reduce the forecast errors}

Given the aforementioned thermal budget for a sequence of 30 days (for two different months), we can estimate the total tendency errors from the relation

$\left.\left.\varepsilon_{\mathrm{ijkl}}=\frac{\partial \mathbf{Q}}{\partial \mathbf{t}}\right)_{\mathrm{ijk} \mathbf{l}}^{\text {mod el }}-\frac{\partial \mathbf{Q}}{\partial \mathbf{t}}\right)_{\mathrm{ijkl}}^{\text {analysis }}$

where $i, j, k$ denote an index for the three coordinates, I denotes the variable.

The model tendency may be written as a sum of the contributions from different terms:

$$
\left.\left.\frac{\partial \mathbf{Q}}{\partial \mathbf{t}}\right)_{\mathrm{ijk} \mathbf{l}}^{\bmod \mathbf{e l}}=\sum_{\mathbf{m}} \frac{\partial \mathbf{Q}}{\partial \mathbf{t}}\right)_{\mathrm{ijklm}}^{\bmod \text { el }}
$$

where $m$ denotes various terms of the model equations. Hence the total tendency error can be represented as

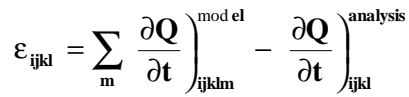

It is possible to define a three dimensional multiplier $\lambda_{\text {ijklm }}$ such that

$$
\begin{aligned}
& \left.\left.\frac{\partial \mathbf{Q}}{\partial \mathrm{t}}\right)_{\mathrm{ijkl}}^{\mathrm{analysis}}=\sum_{\mathbf{m}} \lambda_{\mathrm{ijklm}} \frac{\partial \mathbf{Q}}{\partial \mathrm{t}}\right)_{\mathrm{ijklm}}^{\mathrm{mod} \mathrm{el}} \\
& \text { or } \left.\left.0=\sum_{\mathbf{m}} \lambda_{\mathrm{ijklm}} \frac{\partial \mathbf{Q}}{\partial \mathbf{t}}\right)_{\mathrm{ijklm}}^{\mathrm{mod} \text { el }}-\frac{\partial \mathbf{Q}}{\partial \mathbf{t}}\right)_{\mathrm{ijkl}}^{\text {analysis }}
\end{aligned}
$$

The determination of $\lambda_{\mathrm{ijklm}}$ utilizes the least square minimization procedure based multiple linear regression. Here each of the coefficients is determined from a month long forecast data set. The essential structure of $\lambda_{\mathrm{ijklm}}$ is found to be nearly invariant for two separate computations. Once these $\lambda_{\mathrm{ijklm}}$ are determined, they provide a mean for statistically corrected estimates of the forcing for the dynamics and physics for any of the equations while minimizing (towards zero) the total tendency error.

In the next section we shall present an outline of the physical processes that are part of the model that is being considered here.

\section{Physical Processes}

The components of model physics that are addressed in the partitioning are presented below:

\subsection{Deep cumulus convection}

In the present model the convective heating is by a modified Kuo's scheme where the heating is expressed by:

$$
H_{C}=\mathrm{A}_{\theta}\left(\frac{\theta_{S}-\theta}{\Delta \tau}+\alpha \frac{\partial \theta}{\partial \sigma}\right)
$$

Here $\theta$ is the potential temperature; $\theta_{\mathrm{s}}$ is the potential temperature of a parcel raised up to that vertical level from the earth's surface. $\sigma$ is the vertical coordinate, $\alpha \mathcal{K}$ is the vertical velocity and $\Delta \tau$ is a characteristic cloud time scale (set to 20 minutes here). $A_{\theta}$ is a weighing factor for moist adiabatic heating, following our previous studies. A detailed derivation is presented in Krishnamurti and Bedi (1988).

This is one of several current cumulus parameterization schemes. This scheme involves a mixing of the cloud scale moist adiabatic properties with the environmental properties essentially on isobaric surfaces. This mixing occurs on a time scale $\Delta \tau$ over a fraction $A_{\theta}$ of the grid scale for the thermal mixing. This scheme does not explicitly invoke mass flux (upward) or downdrafts from deep convection.

\subsection{Non-convective rain}

In most of the large-scale global models, the treatment of non-convective rain (also called large scale condensation) is done via a disposition of super saturation. The generation of super saturation occurs through modifications of temperature and moisture (specific humidity) in the model. That modification can occur through all processes in the thermal equation such as horizontal and vertical advection, adiabatic changes, each of the diabatic processes and horizontal and vertical diffusion. Each of these can lead to the possibility of super saturation. The moisture equation contains elements like horizontal and vertical advection, evaporation and condensation, these in turn can also alter the local state to result in super saturation. Thus any of the individual processes in the dynamics and physics of the global spectral model can lead to super saturation. The details of these interactive processes are discussed in Krishnamurti et al. (1998). Basically in the final measure, the super saturation rate is expressed by $\left(q-q_{s}\right) / \Delta t$, where $q$ is the supersaturated state of moisture, $q_{s}$ is the saturation value, and $\Delta t$ is a time step of the spectral model. Non-convective rain is simply measured by $p_{s} / g \int\left(q-q_{s}\right) / \Delta t d \sigma$, where $p_{s}$ is the surface pressure. This disposition of super saturation depends on many other components of the model behavior; hence it is of interest to map the model forecast errors that arise from various non-linearlities.

\subsection{Radiative transfer}

The FSU global spectral model carries two radiative transfer algorithms, one is classical scheme based on look up tables for emissivity (for long wave irradiances) 
and absorptivity (for short wave irradiance), Katayama (1966), Joseph (1966) and Chou (1984). The second method is a band model where the radiative transfers are explicitly computed for numerous bands of absorption spectra, Lacis and Hansen (1974) and Harshvardan and Corsetti (1984). The specification of clouds utilizes a random overlap process where some 8 possible cloud configurations are included following Krishnamurti et al. (1998). In addition to these features, this model includes an explicit computation of surface energy balance where the soil temperature is determined from a balance among incoming and outgoing short and long wave irradiance at the earths surface and the fluxes of sensible and latent heat. Furthermore, this model does interact with a land surface model developed by Bounoua and Krishnamurti (1993 a, b).

Amongst the two methods, the emissivity/ absorptivity method is known from our years of experience to have larger errors, and this appears as a better candidate for the extraction of errors by the proposed method of this paper. With that in view we have utilized the absorptivity/ emissivity method for the proposed experiments. A derivation of the radiative flux convergence is not presented here and can be seen in considerable detail in Krishnamurti et al. (1998).

\subsection{Rest of physics}

Our designation of rest of physics is somewhat arbitrary. It includes all those areas, which, together with the cumulus parameterization, non convective heating, and total radiative heating (or cooling) constitutes the entire physics of the FSU model. Going over the entire structure of the FSU global spectral model, this 'rest of physics' includes the following components:

1) In the vorticity equation, the friction term is $\hat{\mathbf{k}} \cdot \nabla \times$ of the frictional force per unit mass of air. This contains a fourth order horizontal diffusion, vertical diffusion, surface fluxes of momentum and its disposition in the planetary boundary layer (PBL). The surface fluxes of momentum are defined on the basis of surface similarity theory and the PBL fluxes are based on a mixing length theory where the exchange coefficient is Richardson number dependent, Manobianco (1988).

2) In the divergence equation the divergence $(\nabla$.$) of the$ same frictional force (per unit mass) defines friction. This includes the same four components as in the vorticity equation.

3) The thermodynamic energy equation includes the following additional features that are included in the rest of physics: Shallow convection - here we have followed Tiedke's (1984) vertical diffusion of potential temperature and specific humidity to parameterize the effects of shallow moist convection. This tends to move the vertical distribution of the moist static energy from a conditionally unstable state towards a more neutral stratification. This term turns out to be of some importance in the overall order of terms that are being examined here. Dry convection in our model is invoked only to remove the super adiabatic lapse rates, and is being done via a dry convective adjustment. This tends to cool the lower layers and provide an eddy transfer of heat upwards to warm the upper layers somewhat. This is not a feature of major consequence, it is required for suppressing grid scale computational instability but its overall effect on large scale forecasts is small. The horizontal and vertical diffusion of heat in the thermal equation also play a role in the modification of the temperature field and these are also a part of this rest of physics. The most important components among these 'rest of physics' are the surface and PBL fluxes of heat and moisture. These are parameterized using the surface similarity theory and the PBL representation (discussed above). The temperature change in the thermal equation and the change of humidity in the moisture equation are affected by these surface and PBL flux convergences.

In the moisture convergence equation the terms containing horizontal and vertical diffusion of moisture and evaporation are included in the category of the rest of physics. The horizontal diffusion is based on a fourth order (diffusive) and the vertical diffusion is based on the K-theory. Evaporation estimates are provided by the similarity theory, Krishnamurti et al. (1998). Precipitation is computed from both convective and nonconvective physics.

\section{Distribution of Partitioned Component Weights}

We shall next discuss the results from the second part of our computations, i.e., regression of component tendencies towards total observed tendencies. To illustrate this concept, we shall show results on day- 6 of forecasts some of the salient weights of the thermal equation at $\sigma=0.346$ (roughly the $350 \mathrm{hPa}$ level), based on data for November 2001 in Fig. 2. The weights of advective and the rest of dynamics shown in Figs. $2 a$, and $2 \mathrm{~b}$ respectively are generally close to 1.0. This implies that the tendency errors for these respective terms of the model equations are not large at day 6 of forecasts. We furthermore note that the patterns of these weights are quite similar for the advective dynamics and the rest of dynamics, indicating that similar corrections are being made to these terms. However it should be noted that geographic distributions of the advective dynamics and the rest of dynamics tend to be nearly equal but of opposite sign. This suggests that similar weights (all positive and nearly equal) provide corrections for the tendencies of advective dynamics and the rest of dynamics (whose magnitudes have opposite signs). Advective dynamics is being underestimated (perhaps a lack of resolution issue) whereas the rest of dynamics (dominated by divergence) is being overestimated.

The distribution of weights based on datasets from November 2001 for the non-convective precipitation of the model is shown in Fig. 2c. They are also found to have very similar structures. Weights slightly in excess 
of 1.0 can be seen all along the zonal belts of $30^{\circ} \mathrm{S}$ to 50 ${ }^{\circ} \mathrm{S}$ and $30^{\circ} \mathrm{N}$ to $45^{\circ} \mathrm{N}$. Over these shaded regions the model is underestimating the non-convective rain, whereas over most of the unshaded regions the model appears to overestimate in many places (the unshaded areas). The mid latitude belt between $30^{\circ}$ and $50^{\circ}$ carries a large proportion of stable layer clouds where the model appears to underestimate non-convective heating. The disposition of super saturation for non convective heating in our model uses saturation criteria of 90 percent. Since the model seems to overestimate non convective rain, a rising of this criterion could possibly lower the non convective rain over many of unshaded areas of Fig. 2c. Some systematic studies need to be carried out to improve the non convective rain. It must however be noted that the magnitude of the weights in Figs. $2 c$ for non-convective rain are in fact quite close to 1.0. Thus the desired correction for day 6 of forecasts is in fact quite small. This implies that the current formulation of non convective rain require only small improvements.

The weights for deep convection are shown in Fig. $2 \mathrm{~d}$. The tropical weights largely reside between 0.0 and 0.8 suggesting an overall overestimation of the convective heating by the model. The FSU modified Kuo's scheme (Krishnamurti et al. 1983) adapted here in this study contains a large scale and mesoscale moisture convergence estimate to determine the fraction area of grid squares that carry deep moist adiabatic cloud elements. In this formulation, two of the parameters, a mesoscale convergence parameter and a moistening parameter are expressed as linear functions of lower tropospheric relative vorticity and a mean vertical velocity. This relationship was determined from the use of linear regressions and GATE data sets, Krishnamurti et al. (1980, 1983). A number of uncertainties clearly exist in the formulation of these simple cumulus parameterization schemes. Figure $2 d$ is simply conveying the message that a close match of the temperature tendencies to the 'observed-analysis based estimates' is obtainable if the heating rates of this modified Kuo's scheme were lowered by roughly 50 to $80 \%$. This procedure does not tell us where precisely, within the convective algorithm, those errors are arising. In principle, even that information is extractable if the details of the physical parameterization code were laid out in a component form for this multiplier exercise. We are not presently carrying out this study to such a degree of detail. In Fig. $2 d$ it can also be seen that the weights due to deep convection in the polar latitudes generally exceed 0.8 . These fields are somewhat spotty because deep convection is very much smaller in magnitude compared to the tropics. This region is not being emphasized in this study. Figure $2 e$ represents the weights pertaining to contribution from radiative transfer. We notice that the weights are almost uniform over the tropics.

Weights for the rest of physics shown in Fig. $2 f$ include the surface and planetary boundary convergence of fluxes of heat, moisture, and the treatment of shallow convection as some of the major contributors in this area. A preponderance of blue and green shading denotes area where these weights can be as much as $\pm 60 \%$. The blue shading carrying positive weights between 0 and 0.8 signifies that the temperature change is being overestimated in those places, which are coincident with the heavy rain areas. The green areas carrying negative weights imply that in these regions the rest of physics contributes to a cooling, this generally happens to be non-precipitating regions that abound in shallow convection.

In the extra tropics, immediately poleward of $45^{\circ}$ latitude, weights between 0 and 0.8 are seen over the north Pacific and the southern Indian ocean where the rest of physics appears to be overestimating these temperature changes. These are regions of strong frontal activity and polar air outbreaks. The model's boundary layer and shallow convection are possible contributors to large temperature change, the weights less than 1.0 in these regions is suggesting a need for correcting this physics towards lower temperature tendencies.

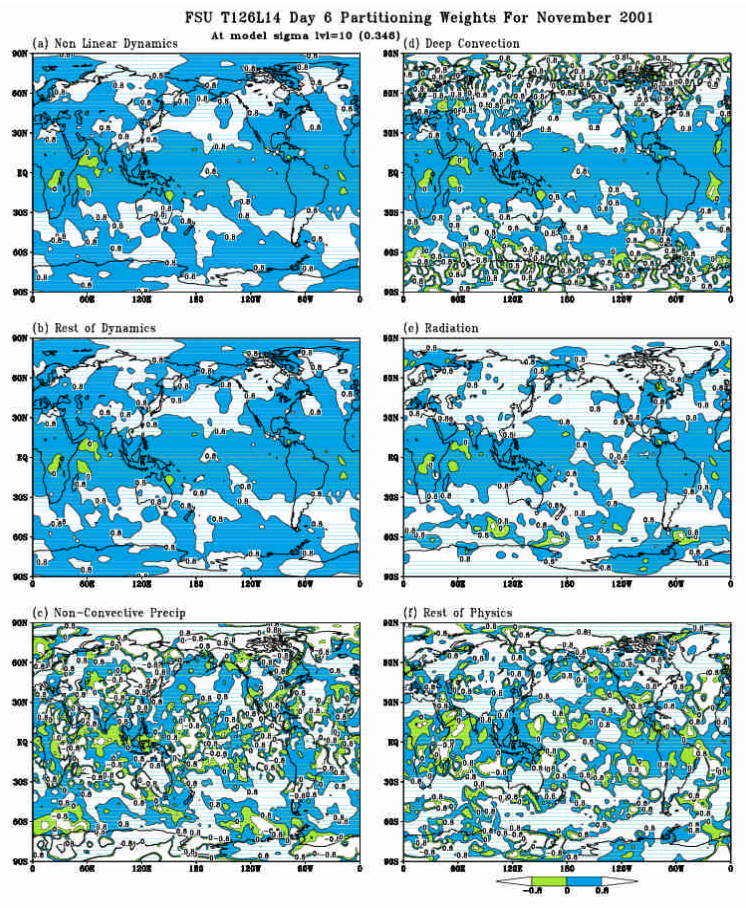

Figs. 2a-f The distribution of partitioning weights for November 2001 at a single level $(\bullet=0.346)$, roughly at the $350 \mathrm{hPa}$ level. In sequence, these are distributions for non-linear dynamics, deep cumulus convection, rest of dynamics, non-convective physics, Radiation and the rest of physics.

\section{Reduction of Total Errors}

The day 6 forecast errors from the FSU model for the total tendency of temperature at $\sigma=0.346$ (close to $350 \mathrm{hPa}$ level) are shown in Figs. 3 and 4. These are the monthly averaged errors (units K/day) for November 
and December 2001 respectively. These errors are of the order of $\pm 1^{\circ}$ to $\pm 2^{\circ}$, especially over the middle latitudes (Figs. $3 a$ and $4 \mathrm{a}$ ). The tropical errors are of the order of $\pm 0.5^{\circ}$ to $\pm 1{ }^{\circ} \mathrm{C}$. With the introduction of the multipliers $(\lambda)$ obtained through regressing the values of the individual contributions to the thermal equation against the observed total tendencies, the total errors are considerably reduced. The goodness of fit of the regression is shown from the reduced errors in Figs. 3b and $4 \mathrm{~b}$. Here we see a uniform reduction of errors to within $\pm 0.5^{\circ}$. The advantage of this representation is that we are now able to extract estimates of the component errors from the dynamics and physics of the model and use that information to reduce the total error.

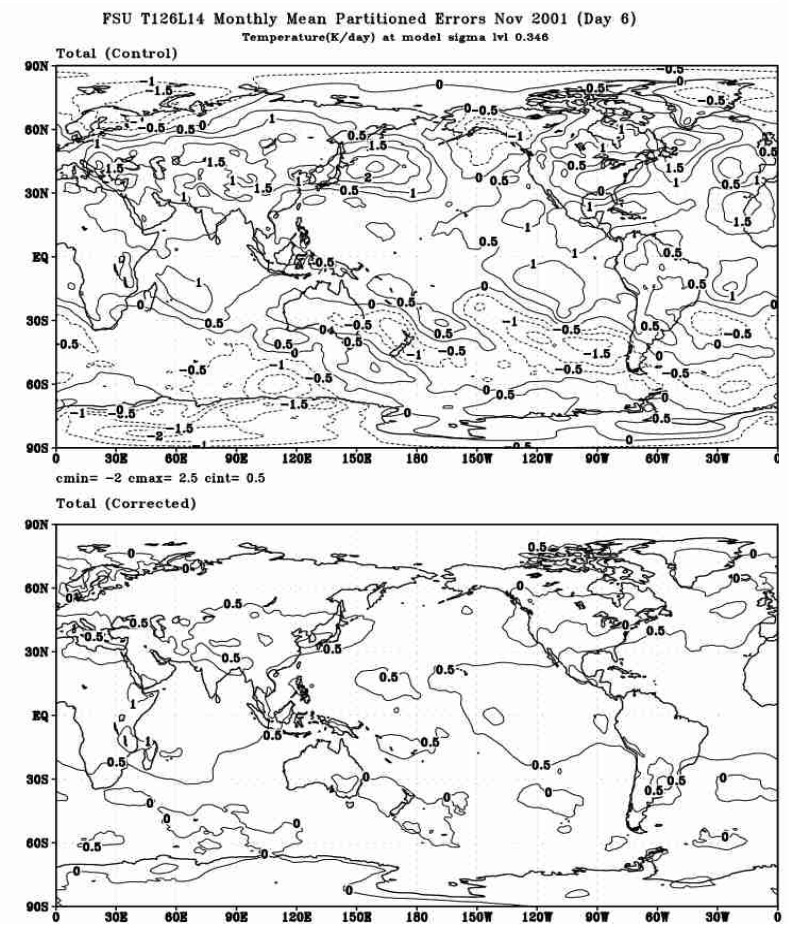

Fig. 3 Total temperature tendency error $\cdot K /$ day for day 6 of forecasts at $\cdot=0.346$ level $(p=350 \mathrm{hPa}$ level) for November 2001. a. Original control run b. After the correction are applied.

To validate the partitioning methodology adapted here, the contribution from deep convection towards the total temperature tendency is compared with the observed rainfall and is shown in Figs. $5 a$ and $5 b$ for the month of December 2001. The spatial distributions of both these fields shown here are closely related to deep convective processes of the tropics. Contribution to the upper tropospheric total temperature change arising from the deep convection, shown in Fig. $5 \mathrm{a}$, bears a very strong resemblance to the TRMM/SSM-I based monthly mean rainfall displayed in Fig. 5b. This temperature change is a measure of the diabatic heating from the parameterized cumulus convection and merely indicates the strength of the proposed method.
This is also a strength of the 'with and with' process invoked here.

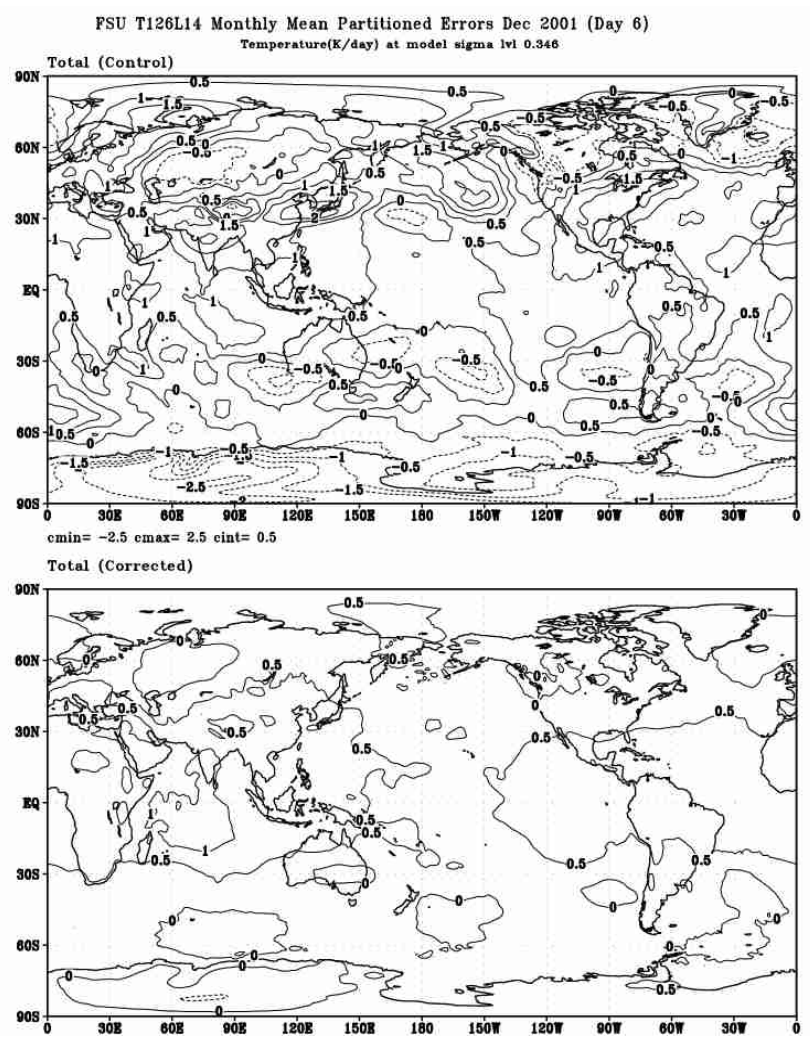

Fig. 4 Same as Fig. 3 but for December 2001.

(a)

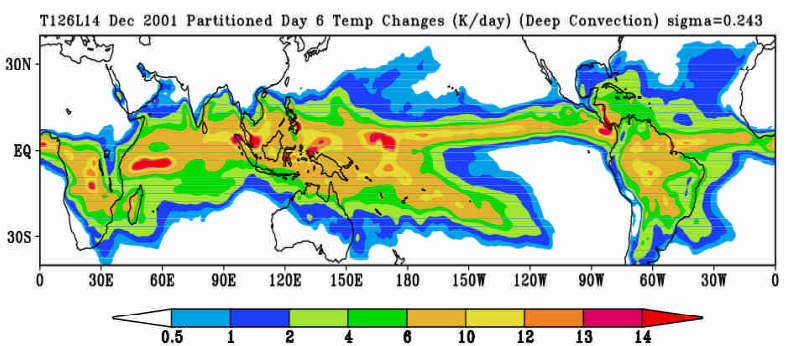

(b)

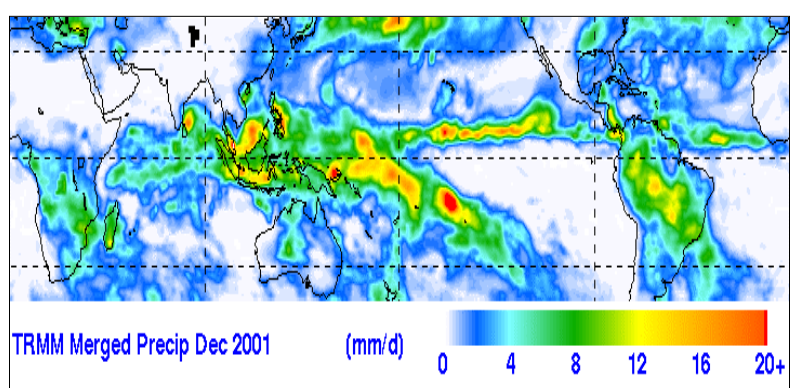

Fig. 5 a. Partitioned contribution to mean temperature tendencies from deep convection for December 2001, at the sigma level $\bullet=0.245$ (roughly $250 \mathrm{~h} \mathrm{~Pa}$ level), units 
-K/day. b. Monthly mean precipitation (mm/day) for December 2001 from TRMM observations

We shall next examine the mean partitioned fields of the temperature changes (K/day) for day 6 of forecasts for December 2001. These will be examined for both the upper and the lower troposphere. We shall illustrate the component contributions from deep convection, radiation and the rest of physics. These are shown for the original model run (control) and for those that include the multipliers (corrected). The contribution from advective dynamics, the rest of dynamics and the non-convective rain are not shown since they did not contribute much to the overall total change. For the upper troposphere ( $\sigma=0.245$, close to $250 \mathrm{hPa}$ level) the mean component temperature changes due to deep convection for the original run (control) and the corrected fields are shown in Fig. 6. For the original model run, temperature changes are of the order of 4 to $10 \mathrm{~K}$ all along the ITCZ and SPCZ (Fig. 6a). The winter season rain areas of South Africa and South America also exhibit large temperature changes in this original experiment. When the multipliers are applied to these results, a marked reduction of the temperature tendencies is noted in Fig. $6 \mathrm{~b}$ near the $250 \mathrm{hPa}$ level. The modified Kuo scheme used in the present study is quite different from the classical Kuo scheme (Kuo, 1965). The former appears to overestimate the heating rates, at horizontal resolution of the order of $100 \mathrm{~km}$ or higher over the upper troposphere whereas the latter is known to underestimate the heating. The corrected fields show a decrease of heating at this level compared to the control run.

In Figs. $6 c$ and $6 d$ we show the tendencies of temperature change from the control run and the corrected values respectively at $\sigma=0.245$ (roughly the $250 \mathrm{hPa}$ level) arising from the radiation algorithm. Along the ITCZ the cooling rates in the initial run were around 1.5 to $2 \mathrm{~K} /$ day while the corrected estimates show lesser cooling rates in the range of 0.5 to $1 \mathrm{~K} /$ day. This is consistent with the results from more vigorous convection scheme of the initial run, which was corrected towards lower heating rates. The initial run extends moist air farther upward calling for a denser population of high clouds (and related stronger cloud top cooling) that is being corrected here.

The temperature changes arising from the rest of physics shown in Figs. 6e and 6f are largely contributed by shallow moist convection and the PBL physics. This has a small effect in the upper troposphere. Comparing the results of original run displayed in Fig. 6e and the multiplier based corrected field in Fig. 6f, we note that the temperature changes of the order of -0.2 to -0.6 $\mathrm{K} /$ day are largely the same in both representations at this level from this category.

We next illustrate these same component fields of temperature tendencies at the lower troposphere $\sigma=0.875$ (close to $850 \mathrm{hPa}$ level) in Fig. 7. The temperature changes in the original and the corrected versions are small for cumulus convective heating compared to upper troposphere over most of the regions, as can be seen in Figs. 7a and 7b. The ITCZ over the eastern Pacific Ocean showed a temperature change of the order of 2 to $4 \mathrm{~K} /$ day in the original experiment, which was entirely removed by introducing the multipliers. Results from the radiation experiment shown in Figs. 9c and 9d indicate a net cooling of the order of 1 to $3 \mathrm{~K} /$ day over many regions. Overall that is somewhat reduced in the tropics and enhanced over the subtropics and extratropics of the northern hemisphere. The subtropical eastern oceans in the southern hemisphere evidently carry a large amount of coastal stratus and fog (see off the coast of South America), clearly this approach is pointing to an error over these regions that is being corrected by requiring an enhanced local cooling. This is evidenced by sharper local gradients over the eastern oceanic regions. These are the types of systematic corrections, the proposed method provides for these components of the model physics.

FSU T128L14 Dec 2001 Mean Partitioned Changes Temp(K/day) Day 6: Sigma=0.245
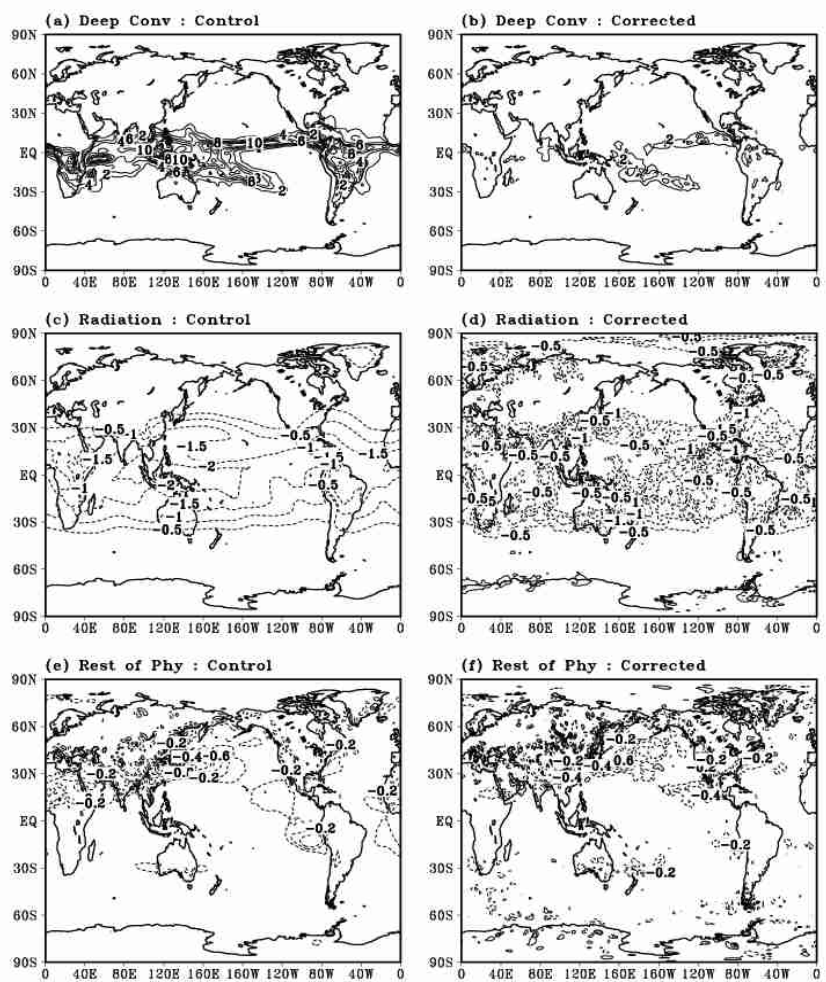

Fig. 6 Partitioned contributions to mean temperature tendencies for December 2001, at the sigma level $\cdot=0.245$ (roughly $250 \mathrm{~h} \mathrm{~Pa}$ level), units $\cdot \mathrm{K} /$ day. (a) original results from deep convection, (b) corrected values, (c) original results from radiation, (d) corrected values, (e) original results from the rest of physics and (f) corrected values.

Finally we also look at the rest of physics in this same context at the $\sigma=0.875$ level (close to $850 \mathrm{hPa}$ level) in Figs. $7 e$ and 7f. Sensible heat fluxes and 
shallow convective heating result in such large values north of the ITCZ, east of the SPCZ and the West Pacific coastal region near $30^{\circ} \mathrm{N}$. The temperature change over these regions ranges from $1 \mathrm{~K} /$ day to as large as $4 \mathrm{~K} /$ day. The introduction of the multiplier shown in Fig. 9f reduces their magnitudes considerably. At this lower level the boundary layer and shallow convection dominates this category of "rest of physics". Contrary to that, it may be noted that the contributions from this rest of physics were quite small near the 250 $\mathrm{hPa}$ level (Figs. 6e and 6f).
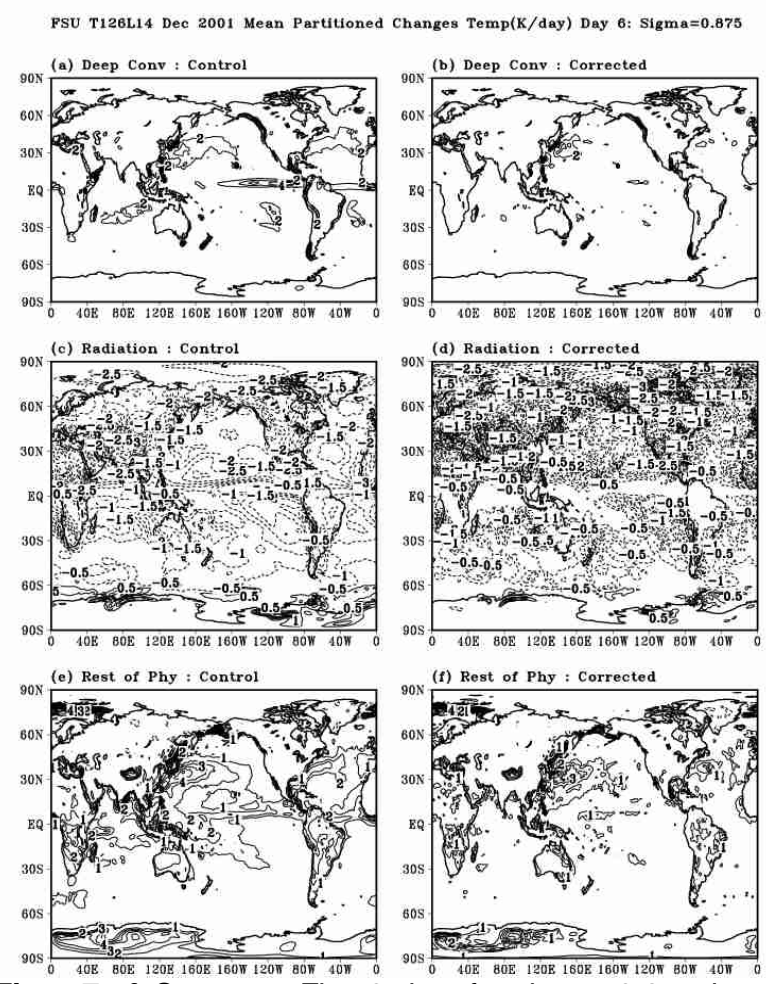

Figs. 7a-f Same as Fig. 6, but for the $\bullet=0.875$ level (close to the $850 \mathrm{hPa}$ level)

\section{Correction for Vertical Structures}

Issues that are most relevant to the present paper are the vertical distribution of heating, moistening, and the parameterized sub-grid scale fluxes. The method proposed here aims to assess errors in these vertical profiles for the individual physical processes. Although the proposed method statistically isolates these errors in the physical parameterization algorithms, it does not automatically provide correction for such algorithms. This approach tells us whether a given parameterization scheme is warming, cooling, moistening or drying the atmosphere at a particular vertical level more than what the observations (i.e., the analysis) suggest.

A number of different vertical cross sections for the original as well as the multiplier based corrected fields over several parts of the globe were constructed for the dynamics and physics contributions to the total change of temperature (K/day). These cross sections are shown in Figs. 8-12. Such cross sections facilitate identification of source of errors in the vertical structures of the component tendencies and means to correct them through the statistical approach adapted in this study.

A longitude-height cross section shown in Figs. 8a and $8 \mathrm{~b}$ for the near equatorial belt $5^{\circ} \mathrm{S}$ to $5^{\circ} \mathrm{N}$ illustrates a very marked reduction of temperature change. The original day 6 forecast calls for temperature changes in the range 4 to $12 \mathrm{~K} /$ day. This is especially pronounced near $120^{\circ} \mathrm{E}$ to $150^{\circ} \mathrm{E}$ longitudes. The multipliers correct these temperature changes to 1 to $2 \mathrm{~K} /$ day. The original heating rates along the ITCZ were too large with values of temperature changes of the order of $10 \mathrm{~K} /$ day. Noting that these are monthly averages (for December 2001), the corrected number of 1 to $2 \mathrm{~K} /$ day do seem more in line. In a series of papers, Yanai et al. (1973) reported on the observation based estimates of the well known 'apparent heat source' $Q_{1}$ over several tropical sites. Their estimates were generally of the order of 5 to 6 $K /$ day for $Q_{1}-Q_{R}$, where $Q_{R}$ is the radiative heating. Since $Q_{R}$ is of the order of 2 to $3 \mathrm{~K} /$ day and an estimate of $Q_{1}$ around 5 to $6 \mathrm{~K} /$ day are thus consistent with our corrected estimates of $Q_{1}-Q_{R}$.
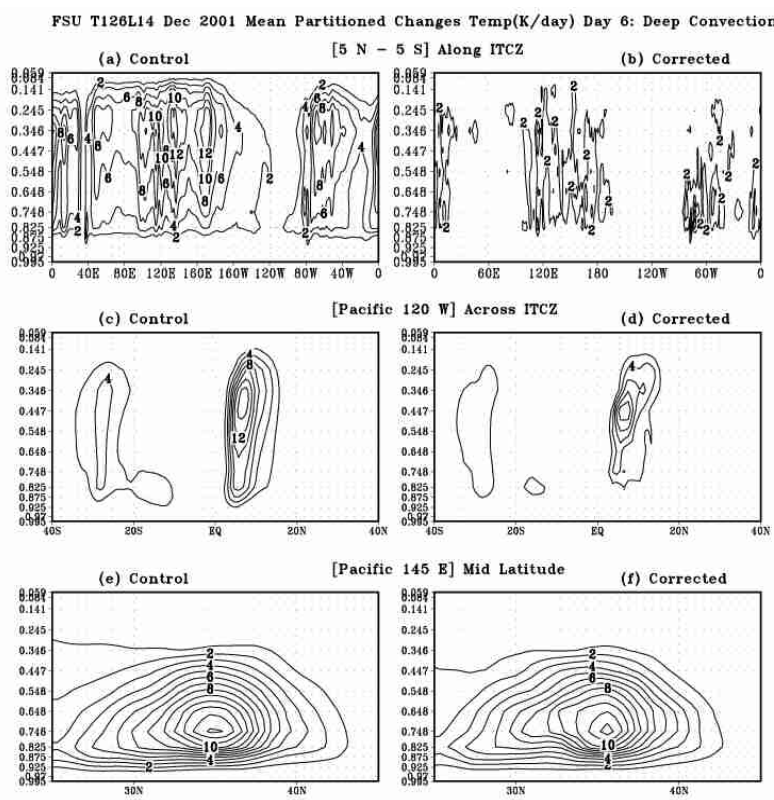

Fig. 8 Vertical cross sections of total temperature change from deep convection for December 2001. Units' $\cdot K /$ day at various selected sites. (a) original values along the ITCZ, (b) corrected values, (c) original values across the ITCZ over the Pacific Ocean at 120 W, (d) corrected values, (e) original values over the middle latitudes at $145 \mathrm{E}$ from south to north passing from $25 \mathrm{~N}-45 \mathrm{~N}$, and (f) corrected values

Latitude-height cross sections of temperature tendencies across the Pacific ITCZ near $120^{\circ} \mathrm{W}$ are shown in Figs. $8 \mathrm{c}$ and $8 \mathrm{~d}$. We note some reduction of temperature tendencies near $10^{\circ} \mathrm{N}$ from the corrections. The largest heating rates are reduced from $14 \mathrm{~K} /$ day to roughly $10 \mathrm{~K} /$ day. The height of maximum heating is lowered from roughly $450 \mathrm{hPa}$ to $500 \mathrm{hPa}$ by these corrections. In contrast, over the middle latitudes the 
temperature change from convection hardly alters the vertical structure as is seen in Figs. $8 \mathrm{e}$ and $8 \mathrm{f}$. In these middle latitude cross sections the level of maximum heating from convection is much lower.

We shall next illustrate the vertical cross sections over three selected regions across SPCZ, Brazil and Bay of Bengal in Fig. 9. A more drastic reduction of the temperature change is noted over these regions. These vertical cross sections are drawn across the plane connecting two points over each of these selected regions in such a way that the region of interest is highlighted in these cross sections. The vertical cross sections shown in Figs. 9a and 9b over the SPCZ region cover the area between $160^{\circ} \mathrm{E}, 5^{\circ} \mathrm{S}$ and $240^{\circ} \mathrm{E}, 27^{\circ} \mathrm{S}$. Here the maximum convective heating is located close to the $350 \mathrm{hPa}$ level $(\sigma=.346)$. We note that the model overestimates the temperature changes with the values of the order of 4 to $10 \mathrm{~K} /$ day, whereas the corrected estimates are around 2 to $4 \mathrm{~K} /$ day and are located near the $400 \mathrm{hPa}$ level $(\sigma=.4)$. The vertical cross sections over Brazil covering the region between $280^{\circ} \mathrm{E}, 10^{\circ} \mathrm{S}$ and $330^{\circ} \mathrm{E}, 10^{\circ} \mathrm{N}$ is shown in Figs. $9 \mathrm{c}$ and $9 \mathrm{~d}$. Here the control run (Fig. 9c) has temperature changes due to convection is of the order of $14 \mathrm{~K} /$ day at around 350 $\mathrm{hPa}(\sigma=.346)$ level. The corrected fields in Fig. 9d show a drastic reduction of these tendencies to around 4 $\mathrm{K} /$ day with the maximum residing near the $750 \mathrm{hPa}$ level $(\sigma=.748)$. The longitude-height cross section along $14^{\circ} \mathrm{N}$ over the Bay of Bengal displayed in Figs. 9e and $9 f$ shows a corresponding reduction of temperature from $12 \mathrm{~K} /$ day to $6 \mathrm{~K} /$ day with the level of maximum convective heating being lowered from $350 \mathrm{hPa}$ level $(\sigma=.346)$ to approximately at $550 \mathrm{hPa}$ level $(\sigma=.548)$.
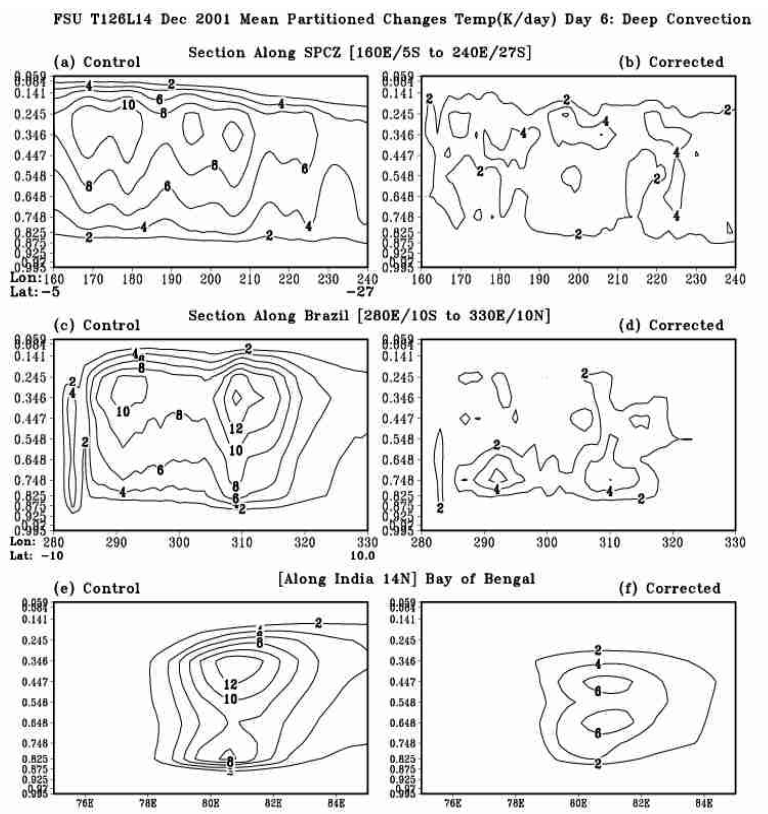

Figs. 9a-f Same as Figs. 8a-f but these sections are over regions of SPCZ (South Pacific Convergence Zone), Brazil and the Bay of Bengal.
Although the model based temperature changes were reduced over several regions, the changes over land areas were larger from these corrections. There are other instances where we noted that the temperature changes from applying these corrections were in fact increased. This was true for the 'rest of physics' component. Figure 10 shows the portioned changes due to the 'rest of physics' over different regions. Here the corrections suggest that the model does not have a robust representation of temperature change from shallow convection and PBL physics. This suggests the directions along which the lower tropospheric modeling needs to be improved. Another noteworthy feature seen in Fig. 10 is that the temperature tendencies contributed by 'rest of physics' are restricted to the lower levels only. The multipliers corrects the temperatures in all of the tropical convective areas as seen in the cross section diagrams across ITCZ (along $120^{\circ} \mathrm{W}$ in the tropics) shown in Figs. $10 \mathrm{a}$ and $10 \mathrm{~b}$, along the entire near equatorial region between $5^{\circ} \mathrm{N}$ and $5^{\circ} \mathrm{S}$ in Figs. $10 \mathrm{c}$ and $10 \mathrm{~d}$, and in the Bay of Bengal region (between $75-85^{\circ} \mathrm{E}$ along $14^{\circ} \mathrm{N}$ ) in Figs. 10e and $10 \mathrm{f}$.

FSU T126L14 Dec 2001 Mean Partitioned Changes Temp(K/day) Day 6: Rest of Phy

(a) Control [Pacific $120 \mathrm{~W}]$ Across ITCZ
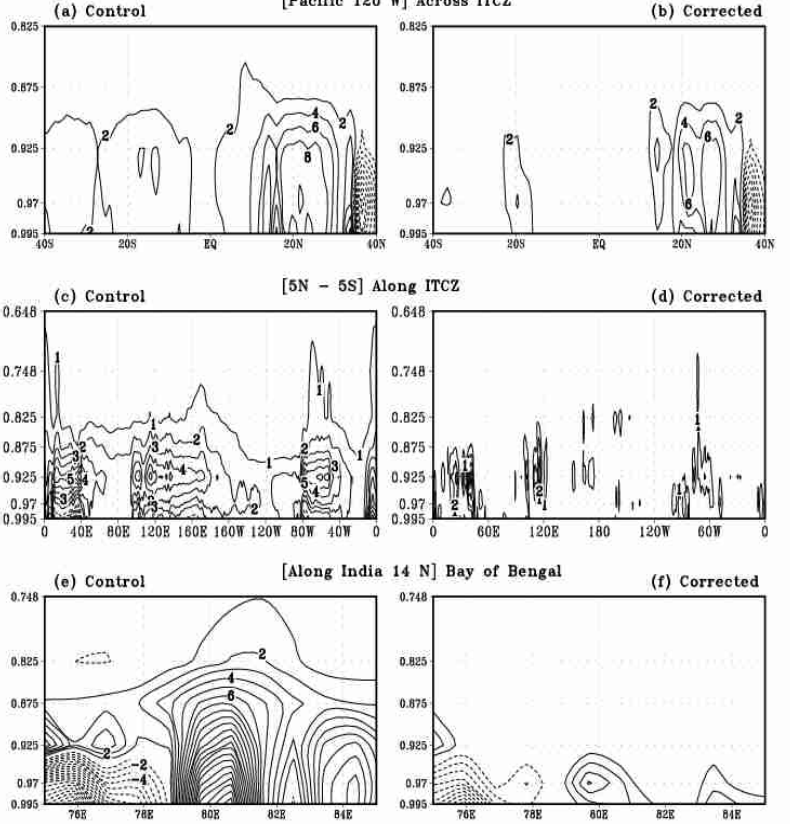

Figs. 10a-f Same as Figs. 10a-f but for the tendency contribution from the 'Rest of Physics' for East Pacific, across ITCZ, along ITCZ and the Bay of Bengal.

The corrections for the temperature changes from the nonlinear advective dynamics are in general quite small for day 6 of forecasts for most of the regions around the globe. An exception was the region over the Bay of Bengal between $75-85^{\circ} \mathrm{E}$ along $14^{\circ} \mathrm{N}$ where we noted a drastic lowering in the intensity and location of the advective temperature changes. These results are displayed in the longitude-height cross sections in Figs. $11 \mathrm{a}$ and 11b. The western Bay has positive changes whereas the eastern Bay encountered cooling from nonlinear advection. In the original model large changes 
were located near the $75 \mathrm{hPa}$ level $(\sigma=.075)$ that appeared clearly erroneous. The corrections moved those down to the middle troposphere. The amplitudes were reduced by almost one-third to half of the model values by these corrections. The structure of the temperature change from the rest of dynamics shown in Figs. $11 \mathrm{c}$ and $11 \mathrm{~d}$ over the same region almost always appears to be opposite in sign to that the advective dynamics. The magnitudes of these are generally comparable. The rest of dynamics includes many terms; the most prominent of these arise from the divergence. Among other interesting features, we noted a marked reduction of temperature change for the non convective rain for the control run as compared to the corrected estimates. An illustration over the central Bay of Bengal along $14^{\circ} \mathrm{N}$ in Figs. $11 \mathrm{e}$ and $11 \mathrm{f}$ shows a reduction from $10 \mathrm{~K} /$ day to almost $6 \mathrm{~K} /$ day and an overall reduction in the area covered by this temperature change. As stated previously this may have to do with the choice of too low a value (80\%) for the threshold relative humidity to define grid scale saturation.
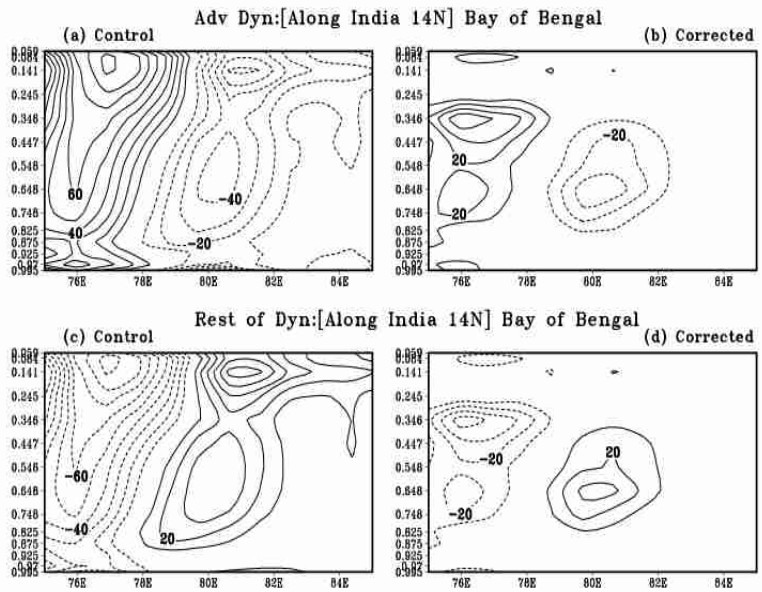

(e) Control

Non-Conv Rain:[Along India 14N] Bay of Bengal
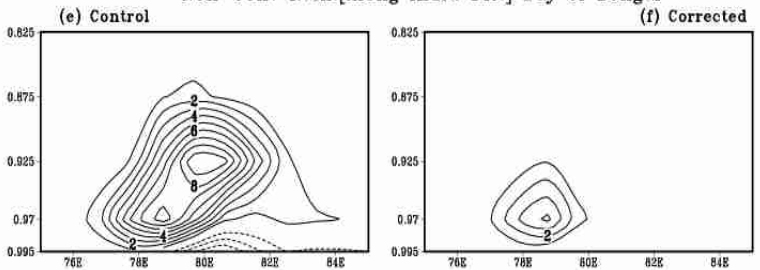

Figs. 11a-f Same as Figs. 8a-f but for temperature tendencies from the Advective Dynamics, Rest of Dynamics, and Non-Convective physics for the Bay of Bengal region.

Because the model, in general, is more active in terms of convection and rain, the atmosphere tended to be more moist in the control run compared to observations. Consistent with that, the multipliers suggested a lowering of the magnitudes of the temperature tendencies arising from radiation over most regions such as the ITCZ, Central Pacific Ocean, and the Asian monsoon belt. In relatively dry regions such as the Eastern Pacific, the corrections to temperature tendencies from radiation were very small. These results were illustrated in Figs. $12 \mathrm{a}$ and $12 \mathrm{~b}$ where the middle latitude-height cross section of temperature changes due to radiation from the control run and corrected fields across the Eastern Pacific along $145^{\circ} \mathrm{E}$ (between $25-45^{\circ} \mathrm{N}$ ) are displayed. Except for some small regions in the tropics and beyond $40^{\circ} \mathrm{N}$, corrections are almost minimal here for day- 6 of forecasts.

FSU T126L14 Dec 2001 Mean Partitioned Changes Temp(K/day) Day 6: Radiation (a) Control

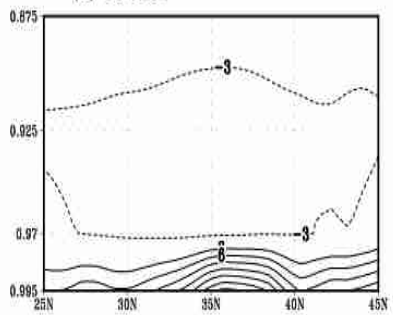

(b) Corrected

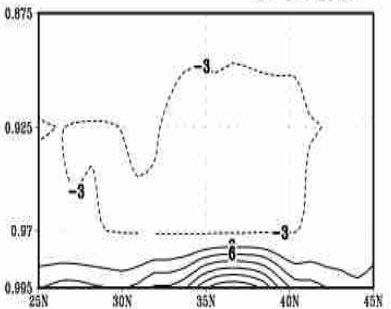

Figs. 12a-b Same as Figs. 8a and 8b but for tendencies from radiation for East Pacific Region across latitudes $25 \mathrm{~N}$ to $45 \mathrm{~N}$.

\subsection{Vertical Profiles}

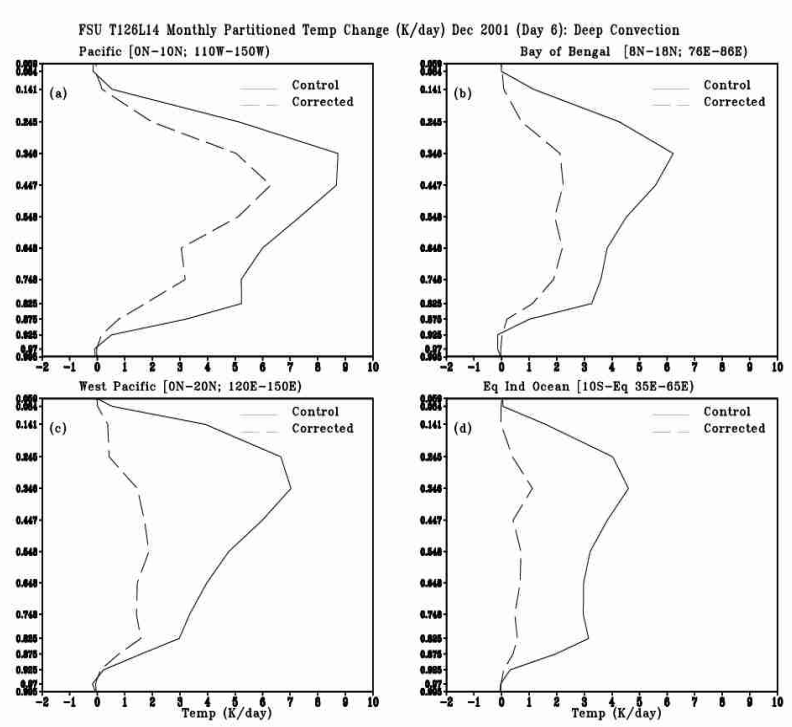

Fig. 13 Vertical profiles of deep convection related temperature tendencies $(\cdot \mathrm{K} /$ day $)$ over selected regions. (a) near equatorial East Pacific Ocean, (b) Bay of Bengal, (c) tropical West Pacific ocean, and (d) the equatorial Indian Ocean. Solid lines show profiles from the original run, dashed lines the corrected values.

We shall next show a number of vertical cross sections of the heating profiles. In each of the profiles we show two curves, a solid line showing the vertical distributions from the original runs, and the dashed lines incorporating the multipliers $(\lambda s)$ such that the model tendencies (including the $\lambda$ ) are very close to the observed total tendency. The vertical structural change of convective heating averaged over 30 days 
(December 2001) were examined over the eastern and western Pacific ocean, Bay of Bengal and the equatorial Indian ocean and are illustrated in Figs. 13a-d respectively. The latitude and longitude belts are indicated on top of each panel. The solid lines essentially show the heating from the original model run on day 6 of forecasts. The corrected estimates (shown by the dashed line) are invariably smaller in magnitude. The level of maximum heating was not significantly altered by the correction. Although the level of maximum heating is generally lower for the classical Kuo's scheme, the modified scheme used here, Krishnamurti and Bedi (1988), evidently has already corrected for this deficiency of the Kuo's scheme. These reduced values of heating are consistent with the lower values of the errors of overall observed total temperature tendencies shown in Fig. 5b.

\section{Concluding Remarks}

There are some intriguing aspects to these forecast model computations we have presented here. The classical 'with and without' types of numerical experiments suffer from the fact that they do not recognize the continual co-evolution of dynamical components with the physical components. Thus if the effects of cumulus convection were to be continually suppressed to assess what its absence does, then one has not allowed for the fact that cumulus convection continually coexists with the rest of the model. In Krishnamurti et al. (1996) we proposed a 'with and with' strategy where the coexistence was addressed. This required a massively parallel computer with sufficient storage to take on a vast bookkeeping task. Here we are dealing with a global model that carries 5 prognostic equations and some 3 diagnostic relations. This 'with and with' strategy accommodates the non-linear coupling among the many equations as the variables undergo their interplays with each other at each time step. For instance suppressing the deep cumulus convection algorithm, in the 'with and with' strategy, impacts the tendency of all other prognostic variables such as vorticity, divergence, temperature, specific humidity and the log of the surface pressure. This procedure is used here to estimate the accumulated tendencies for each of the forcings such as nonlinear advective dynamics, rest of dynamics, deep cumulus convection, large scale condensation physics, radiative transfers and the rest of the physics. The estimates of various terms for any prognostic equation (such as the thermal equation) are thus collected on a daily basis over the globe for a month, and they provide a budget for that equation in a new light.

We have shown that these new daily budget data sets still carry forecast errors such that the total model tendencies do not match the total 'observed' (based on analysis) tendencies. We next collected the time tendencies of each of the forcings for each equation and the 'total observed tendencies' for a string of 30 days. This data set was subjected to a multiple linear regression. This exercise is repeated over two separate months of November and December 2001. This is global forecast where the multipliers are determined at each transform grid point over the entire globe for 14 vertical levels for each of the terms. We have looked at the thermal equation in some detail in this context here. What we note here is that this procedure does provide statistical magnitude of tendencies contributed by the different major forcings of the thermal equation. These are designed to match the total observed tendencies. By this process, we have assessed some of the deficiencies of the FSU global spectral model used here, i.e., its convection scheme, the representation of large scale condensation, radiative transfers and the rest of physics. This provided information on the contributions to the total errors of this model from the different areas of dynamics and physics, and types of errors that arise from a particular physical parameterization. We also provided information on errors in the vertical distributions of physical processes, and displayed the geographical structure of these errors as well.

Thus our computation on the contributions from the physics and dynamics of a model entails two steps - 1) the 'with and with' strategy for a sequence of forecasts and 2) the statistical determination of the multipliers that minimize the total tendency errors. We have found this to be a very robust procedure. Alternatively, we could have avoided step 1 and simply carried out a statistical evaluation of the multipliers from step 2 using model output data sets from the parent forecasts. We noted that the multipliers obtained from the two-step procedure are statistically more significant in a sense that they could explain about $90 \%$ of the total variance of the multipliers and have higher confidence level. The multipliers obtained directly using the componenttendencies from the model forecast data sets could explain only about $40 \%$ of the total variance of the multipliers and have larger spread. The error minimization from this procedure (not shown here) was not very impressive when independently tested for different months of forecast. Results from the two-step procedure are noted to be superior to this direct method.

One could ask if an improved forecast model can be constructed that incorporates such $\lambda$ s explicitly in the model equations. Such a model would be stochastic dynamic and may require ensuring global conservation of mass, moisture and energy. That would be an area of future research. In this context, one could ask whether the multipliers derived from the datasets of one period could reduce the model tendencies for another period. To answer that question, we have taken the $\lambda s$ for the month of November 2001 and applied these to the model forecasts for December 2001 to examine the tendency errors. Those results, for a single grid point, for the entire month of December 2001 are shown in Fig. 14. Here the results of day 6 of forecasts at a single site $\left(93^{\circ} \mathrm{E}\right.$ and $\left.3^{\circ} \mathrm{N}\right)$ for an entire month, December 2001 are analyzed. These are time sections of the vertical structure of temperature. Figure $14 \mathrm{a}$ shows the day 6 analyses of temperatures (based on 
observations and assimilation using ECMWF data sets). The day 6 temperature errors from our initial uncorrected forecasts are shown in Fig. 14b. These errors are of the order of 1 to $4 \mathrm{~K} /$ day in the lower troposphere, and about 6 to $8 \mathrm{~K} /$ day over the upper troposphere. The largest errors in the lower stratosphere often exceeded $8 \mathrm{~K} /$ day. Figure $14 \mathrm{c}$ shows the corrected forecast errors when the multipliers based on datasets of December 2001 were used. Here the errors are less than $1 \mathrm{~K} /$ day everywhere. This is more like a cross validation. A very independent check is provided in Fig. 14d where the multipliers for November 2001 were used to carry out the forecasts for December 2001. We note here that the multipliers for November do indeed reduce the errors for the day 6 forecasts for December considerably, to within $1 \mathrm{~K} /$ day. This suggests that further extension of the proposed methodology for stochastic dynamic modeling may be possible.
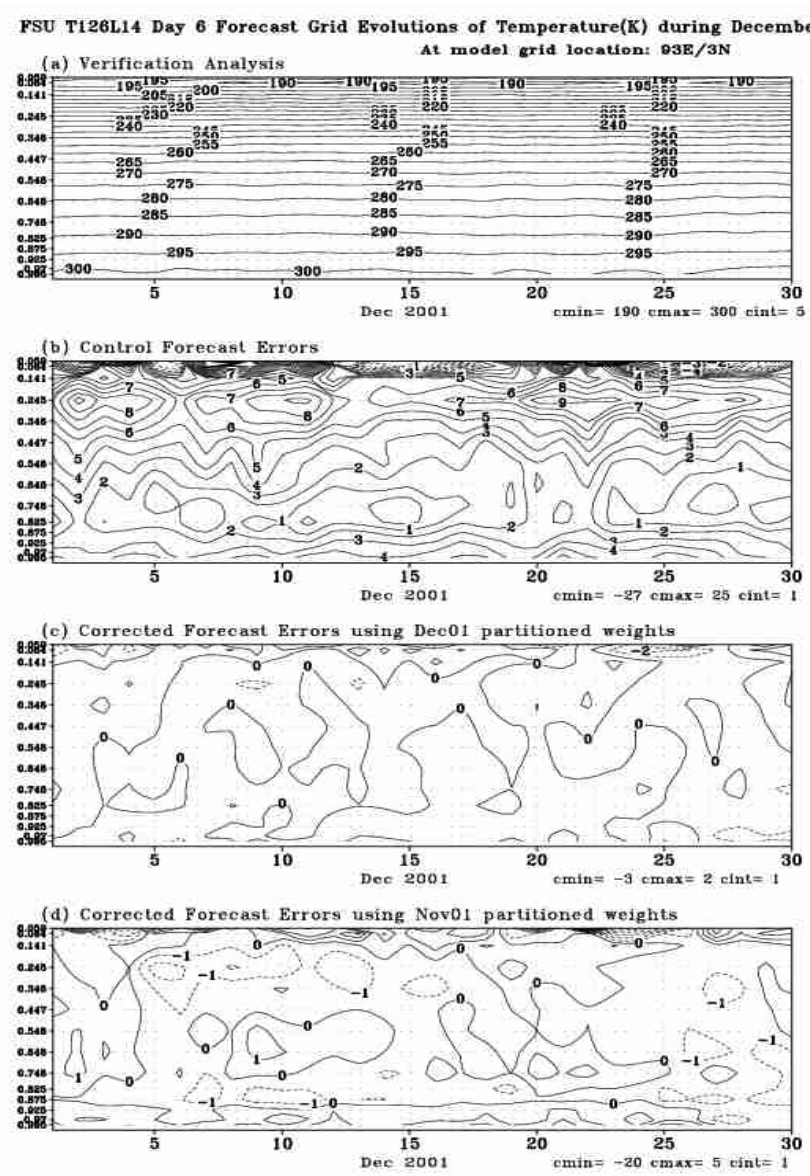

Fig. 14 (a). Verification analysis vertical sections time series for an entire month of temperatures (unit $\bullet \mathrm{K} /$ day). These are for a specific location. (b). Total temperature tendency error from the original experiment for each day of December 2001 (Units $\cdot \mathrm{K} /$ day) at a specific location. (c). Same as Fig. 14b, but for the corrected values where the December 2001 values of multipliers were used to correct the temperatures of December 2001, units $\cdot K /$ day. (d). Same as Fig. 14c, but where the multipliers for November 2001 were used for correcting the day 6 forecasts for December 2001. are:

Some of the salient results on these corrections

1) over most of the tropics the statistical multipliers for deep cumulus convection lie between 0.4 and 0.8 . This implies that the model's 'modified Kuo scheme' over estimates the heating rate by $12 \%$ to $25 \%$. In the vertical, there is no systematic shift of the level of maximum heating; it appears that these overestimates are prevalent over the deep troposphere.

2) There appears to be lack of sufficient upper tropospheric cooling in the tropics where it appears that the high clouds are being underestimated by the model. The correction, based on the multipliers, implies stronger cooling rates that can only be explained as a deficiency of high clouds.

203) The biggest contribution to the category 'rest of physics' came from surface and planetary boundary layer fluxes. Those seem to be overestimated in the model. For correctly explaining the observed total tendencies, those fluxes were reduced by as much as $50 \%$. This is another area where the model's parameterization can be corrected by this procedure.

4) Over several land areas and especially over Brazil we noted that the model was deficient in describing the time tendencies of temperature arising from deep convection. These were in fact reduced by the multipliers by as much as 70 percent in the upper levels.

Overall this approach is built on our trust of the analysis field and the observed total tendencies thus inferred. It is within that constraint that the partitioning of those tendencies is accomplished. Such analysis is what we routinely consider as a benchmark for forecast validation. The same exercise can also be performed with a meso-scale model. If meso-scale observations (and corresponding analysis) were available, the results based on our method might have been sharper and different from this large scale application. The multipliers would, in which case, be different and provide information on the partitioning of dynamics and physics as a resolution dependent story for the same physical parameterization schemes.

This method can in principle be applied to almost any forecast model, i.e., mesoscale, weather and seasonal climate. One needs to determine the number of experiments that are minimally required to assess sound values of the multipliers $\left(\bullet_{{ }_{\mathrm{ijkl}}}\right)$. This may depend on the variability of the fields in the respective models. Once such -'s are determined they provide the possibility for constructing stochastic dynamic models. Present model errors are quite large, as is revealed by the distribution of -'s, thus the avenue of stochastic dynamic models seems like a promising area of extension. It is also important to note that the -'s are only as good as the verification fields. Better data sets 
and better data assimilation can improve the -'s and the results derived there from. A collection of such a family of stochastic dynamic models can be combined towards a multimodel ensemble or superensemble (Krishnamurti et al. 2001) to yield some improved forecasts for the future.

\subsection{Future work}

Suggestion for the future work may include a host of important applications. For example if one takes an entire winter season of global data sets and carry out the exercise of finding the multipliers, those in turn can be applied, for instance, to the life cycle of an extratropical storm. The corrected tendencies can provide an entirely new perspective on the dynamical , thermodynamical and moisture budgets for the entire life cycle of such a system. The final total tendencies for all equations would be nearly balanced to the observed 'analyzed' totals. These results, of course, would be only as good as the total model one deploys and the validation analysis one provides. However, one can say that the models can be made as complete as one desires, and the validation data sets can also be selected from the very best available. This approach is no worse than theoretical approaches where considerable linearization and removal or over simplification of physics is necessary for studying the error growth rates. Here we have a tool that can provide corrections to all of the physical parameterization in three dimensions.

Further work is planned in the following areas: 1) Try different physical parameterization schemes (sequentially) preserving the rest of the models identity. This may reflect the differences in the relative errors of the different schemes. 2) Run multi models in order to compare the distribution of the multipliers of different models. 3) Pose the question of using the multipliers for improved forecast from a single model from the construction of a stochastic dynamic model, and 4) Construction of multi model superensemble following Krishnamurti et al. (2001), after running several stochastic dynamic models in this context.

Acknowledgments. The research work reported here was supported by NOAA Grant numbers NA96GPO400, NA06GPO512, NA16GP1365 and FSU Research Foundation Center of Excellence Award. We acknowledge the data support from the European Centre for Medium Range Weather Forecasts especially through the help of Dr. Tony Hollingsworth.

\section{REFERENCES}

Boer, G.J., 1993: Systematic and random error in an extended range forecasting experiment. Mon. Wea. Rev., 121, 173-188.

Bounoua, L. and T.N. Krishnamurti, 1993a: Influence of soil-moisture on the Sahelian climate prediction .1. Meteorol. Atmos. Phys., 52, 183-203.
Bounoua, L. and T.N. Krishnamurti, 1993b: Influence of soil-moisture on the Sahelian climate prediction .2. Meteorol. Atmos. Phys., 52, 205-224.

Businger, J. A., J.C. Wyngard, Y. Izumi, and E.F. Bradley, 1971: Flux profile relationship in the atmospheric surface layer. J. Atmos. Sci. 28, 181189.

Chang, C. B., 1979: On the influence of solar radiation and diurnal variation of surface temperatures on African disturbances. Rep. 79-3, 157 pp. [Available from Dept. of Meteorology, The Florida State University, Tallahassee, FL 32306].

Chou, M.D., 1984: Broadband water vapor transmission functions for atmospheric IR flux computations. J. Atmos. Sci., 41, 1775-1778.

Curry, J. A., P.V. Hobbs, M.D. King, D.A. Randall, P. Minnis, G. A. Isaac, J.O. Pinto, T. Uttal, A. Bucholtz, D.G. Cripe, H. Gerber, C.W. Fairall, T.J. Garrett, J. Hudson, J.M. Intieri, C. Jakob, T. Jensen, P. Lawson, D. Marcotte, L. Nguyen, P. Pilewskie, A. Rangno, D.C. Rogers, K.B. Strawbridge, F.P.J. Valero, A.G. Williams, and D. Wylie, 2000: FIRE Arctic Clouds Experiment. Bull. Am. Meteorol. Soc., 81, 5-29.

Dalcher, A. and E. Kalney, 1987: Error growth and predictability in operational ECMWF forecasts, Tellus, 39A, 474-491.

Harshvardan and T.G. Corsetti, 1984: Long-wave parameterization for the UCLA/GLAS GCM. NASA Tech. Memo. 86072, Goddard Space Flight Center, Greenbelt, MD 20771, 52 pp.

Heckley, W.A., 1985: Systematic errors of the ECMWF operational forecast model in tropical regions, Quart. J. Roy. Meteor. Soc., 111, 709-738.

Jasper, J.D. and P.J. Meighen, 2000: Model systematic errors, Proc. of $12^{\text {th }}$ Annual BMRC modeling Workshop, 16-20 October 2000, Rep. No. 80, BMRC (Bureau of Meteorology), Australia.

Joseph, J.H., 1966: Calculation of radiative heating in numerical GCMc, Numerical Simulation of Weather and Climate, Tech. Rep. No. 1, Dept. of Meteorology, UCLA, California.

Kanamitsu, M., 1985: A study of predictability of ECMWF operational forecast model in the tropics, J. Met. Soc. Japan, 63, 779-804.

Kanamitsu, M., K. Tada, K. Kudo, N. Sato, and S. Ita, 1983: Description of the JMA operational spectral model. J. Met. Soc. Japan, 61, 812-828. 
Kanamitsu. M. and S. Saha, 1995: Spectral budget of the short-range forecast errors of the NMC Medium Range Forecast Model. Mon. Wea. Rev., 123, 1834-1850.

Kanamitsu. M. and S. Saha, 1996: Systematic tendency errors in budget calculations. Mon. Wea. Rev., 124, 1145-1160.

Kass, E., A. Guldberg, W. May, and M. Deque, 1999: Using tendency errors to tune the parameterization of unresolved dynamical scale interactions in AGCMs, Tellus, 51A, 612-629.

Katayama, A., 1966: On the radiation budget of the troposphere over the northern hemispehere $(\mathrm{I}), \mathrm{J}$. Met. Soc. Japan., 44,381-401.

Krishnamurti, T. N. and H.S. Bedi, 1988: Cumulus parameterization and rainfall rates III. Mon. Wea. Rev. 116, 583-599.

Krishnamurti, T. N., H.S. Bedi, G.D. Rohaly, and D. Oosterhof, 1996: Partitioning of the seasonal simulation of a monsoon climate. Mon. Wea. Rev. 124, 1499-1519.

Krishnamurti, T. N., S. Surendran, D.W. Shin, R.J. Correa-Torres, T.S.V. Vijaya Kumar, C.E. Williford, C. Kummerow, R.F. Adler, J. Simpson, R. Kakar, W.S. Olson, and F.J. Turk, 2001: Real-Time Multianalysis-Multimodel Superensemble Forecasts of Precipitation Using TRMM and SSM/I Products. Mon. Wea. Rev. 129, 2861-2883.

Krishnamurti, T.N., Y. Ramanathan, H. Pan, R.J. Pasch, and J. Molinari, 1980: Cumulus parameterization and rainfall rates I, Mon. Wea. Rev., 108, 465-472.

Krishnamurti, T.N., K.S. Yap, and D.K. Oosterhof, 1991: Sensitivity of tropical storm forecast to radiative destabilization, Mon. Wea. Rev., 119, 2176-2205.

Krishnamurti, T.N., H.S. Bedi, and V.M. Hardiker, 1998: An introduction to global spectral modeling, Oxford University press, 253 pages.

Krishnamurti, T.N., S. Low-Nam, and R. Pasch, 1983: Cumulus parameterization and rainfall rates II, Mon. Wea. Rev., 111, 816-828.

Kuo, H.L., 1965: On formation and intensification of tropical cyclones trhoguh latent heat release by cumulus convection. J. Atmos. Sci., 22, 40-63.

Lacis, A.A., and J.E. Hansen, 1974: A parameterization for the absorption of splar radiation in the Earth's atmosphere, J. Atmos. Sci., 31, 118-133.
Louis, J. F., 1979: A parametric model of vertical eddy fluxes in the atmosphere. Bound-Layer Meteor. $17,187-202$.

Manobianco, J., 1988: On the observational and numerical aspects of explosive east coast cyclogenesis, Ph.D dissertation, Florida State University, $361 \mathrm{pp}$.

Milton, S., D. Cameron, D., and I. Culverwell, 2000: Diagnosing the source of suystematic errors in the U.K. Met. Office global NWP model. Extended abstracts of the $12^{\text {th }}$ Annual BMRC modeling workshop on 'Model Syatematic Errors', BMRC Research Report No. 80, 111-115.

Mohanty, U.C., and K.J. Ramesh, 1995: Systematic errors in the medium range prediction of the Asian summer monsoon circulation. Proc. Ind. Acad. Sci., 104, 49-77.

Molinari, J., and M. Dudeck, 1992: Parameterization of convective precipitation in mesoscale numerical models - A critical review, Mon. Wea. Rev., 120, $326-344$.

Thiebaux, H.J., and L.L. Morone, 1990: Short-term systematic errors in global forecasts: their estimation and removal. Tellus, 42A, 209-229.

Tiedtke, M., 1984: The sensitivity of the time-mean large-scale flow to cumulus convection in the ECMWF model. Proc., Workshop on Convection in Large-scale Numerical Models. ECMWF, Reading, United Kingdom, 297-316.

Tiedtke, M., 1993: Representation of clouds in largescale models, Mon. Wea. Rev., 121, 3040-3061.

Wallace, J. M., S. Tibaldi, and A.J. Simmons, 1983: Reduction of systematic forecast errors in the ECMWF model through the introduction of envelope orography. Quart. J. Roy. Met. Soc. 109, 683-718.

Webster, P.J., and R. Lukas, 1992: TOGA-COARE: The coupled ocean-atmosphere response experiment, Bull. Am. Meteorol. Soc., 73, 1377-1416.

Williamson, D.L., 2002: Time-Split versus process-split coupling of parameterizations and dynamical core, Mon. Wea. Rev., 130, 2024-2041.

Yanai, M., S. Esbensen, and J.H. Chu, 1973: Determination of bulk properties of tropical cloud clusters from large-scale heat and moisture budgets, Mon. Wea. Rev., 30, 611-627. 